\title{
Prognostic and Therapeutic Significance of Androgen Receptor in Patients with Gastric Cancer
}

This article was published in the following Dove Press journal: OncoTargets and Therapy

\author{
Shahrzad Soleymani Fard (D) \\ Mansour Yazdanbod ${ }^{2}$ \\ Masoud Sotoudeh (iD ${ }^{3}$ \\ Davood Bashash iD ${ }^{4}$ \\ Habibollah Mahmoodzadeh (iD) ${ }^{5}$ \\ Kioomars Saliminejad (iD) \\ Seyed Asadollah Mousavi (iD \\ Seyed H Ghaffari (D) ' \\ Kamran Alimoghaddam (iD) ' \\ 'Hematology, Oncology and Stem Cell \\ Transplantation Research Institute, \\ School of Medicine, Tehran University of \\ Medical Sciences, Tehran, Iran; \\ ${ }^{2}$ Department of Surgery, Madaen \\ Hospital, Tehran, Iran; ${ }^{3}$ Digestive \\ Oncology Research Center, Digestive \\ Diseases Research Institute, Tehran \\ University of Medical Sciences, Tehran, \\ Iran; ${ }^{4}$ Department of Hematology and \\ Blood Banking, School of Allied Medical \\ Sciences, Shahid Beheshti University of \\ Medical Sciences, Tehran, Iran; \\ ${ }^{5}$ Department of Surgical Oncology, \\ Cancer Institute, Imam Khomeini \\ Hospital Complex, Tehran University of \\ Medical Sciences, Tehran, Iran
}

Purpose: The clinical studies carried out in the last few decades unequivocally introduced activated androgen receptor (AR) as a pathogenic feature of human malignancies which not only endows cancer cells with survival advantage, but also may be exploited for anticancer interventions.

Patients and Methods: In this study, we have investigated the expression profile of $A R$ and EMT-related genes in fresh gastric cancer (GC), adjacent nontumor and normal gastric tissues, as well as the effect and molecular mechanisms of $A R$ inhibition in GC cell lines.

Results: Amongst $60 \mathrm{GC}$ patients, $66.7 \%$ overexpressed $A R$ that was remarkably correlated with the overexpression of Snail, $\beta$-catenin, Twist 1 , and STAT3. AR overexpression was also remarkably associated with unfavorable outcome $(\mathrm{HR}=3.478, P=0.001)$; however, multivariate Cox regression analysis indicated that it was not an independent prognostic factor ( $\mathrm{HR}=2.089, P=0.056$ ). This study has investigated simultaneous assessment of $A R$ and EMTrelated genes expression and indicated that concurrent overexpression of $A R$ and Snail is an independent unfavorable factor for GC overall survival after adjustment with other variables ( $\mathrm{HR}=2.382, P=0.021)$. Interestingly, the inhibition of $A R$ signaling by potent $A R$ antagonist enzalutamide suppressed cell growth, migration and invasion of GC cells via regulation of apoptosis-, cell cycle-, and EMT-related gene expressions.

Conclusion: Our findings have clinical importance proposing $A R$ as an important prognostic factor involved in GC progression and metastasis, and submit $A R$ inhibition as an appealing therapeutic approach for GC patients, either as a single agent or in a combined-modal strategy.

Keywords: androgen receptor, gastric cancer, epithelial-mesenchymal transition, EMT, prognosis, targeted therapy, enzalutamide

\section{Introduction}

Gastric cancer (GC) currently ranks as the fourth most common cancer and the second most common cause of cancer-related deaths worldwide. ${ }^{1}$ In spite of endorsed and exponential efforts to improve diagnostic and therapeutic strategies, clinical studies have not yet translated into better prospects in GC and many patients are diagnosed at advanced stages with poor prognosis. Based on the fact that the median survival of patients receiving standard chemotherapies is less than 13 months, ${ }^{2}$ there is a crucial need for novel prognostic markers and more effective treatment strategies against advanced GC. Evidence indicated that the incidence of GC is remarkably higher in males over females with a ratio of $2: 1,^{3}$ putting this
Correspondence: Kamran

Alimoghaddam; Seyed H Ghaffari

Hematology, Oncology and Stem Cell

Transplantation Research Institute,

Shariati Hospital, School of Medicine,

Tehran University of Medical Sciences,

North Kargar Avenue, Tehran, Iran

$\mathrm{Tel}+982184902665$

Fax +982188004140

Email alimgh@tums.ac.ir;

shghaffari200@yahoo.com
OncoTargets and Therapy 2020:13 982I-9837

9821

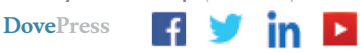

http://doi.org/|0.21 147/0TT. 5265364 
tumor as well as hepatocellular carcinoma (HCC), bladder cancer and pancreatic cancers into a family of malignancies defined as male-predominant cancers. ${ }^{4,5}$ Given this, clarifying the factors which cause sex-related disparity of GC may result in unrevealing pivotal pathways involved in gastric carcinogenesis. Of great interest, the involvement of sex hormone receptors ( $\mathrm{ER} \alpha, \mathrm{ER} \beta, \mathrm{PgR}$ and $\mathrm{AR}$ ) in $\mathrm{GC}$ pathogenesis has been examined in a fair number of studies; ${ }^{1,6-11}$ however, the results are controversial and inconclusive.

Androgen receptor (AR), is a member of the evolutionarily conserved nuclear receptor superfamily, which acts as a transcription factor and regulates the expression of several genes in both androgen-dependent and independent manners. ${ }^{12-14}$ Mounting studies have demonstrated that $\mathrm{AR}$, rather than androgen, functions as an oncoprotein by modulating proliferation and metastasis especially in malepredominant tumors. ${ }^{12-16}$ Several previous studies on HCC revealed that AR-positive patients had a higher rate of tumor recurrence with lower overall survival (OS) when compared to AR-negative patients. ${ }^{17,18}$ Moreover, Okitsu et al showed that phosphorylation of STAT3 and MAPK induced by IL6 leads to the activation of AR in pancreatic cancer cells, which in turn promotes cancer cell migration. ${ }^{19}$ Although there is limited evidence asserting the prognostic significance of AR in GC, 1,8,10,11,20,21 these results are conflicting. While a previous report indicated that AR expression is associated with early TNM stage of $\mathrm{GC}^{7}$ other studies reported $\mathrm{AR}$ as an unfavorable factor for GC outcome. 1,8,11 $^{-1}$

During recent years efforts to suppress the AR pathway have led to the identification of several inhibitors whose anticancer effects were studied thoroughly in various types of tumors such as $\mathrm{HCC}$, prostate cancer, pancreatic cancer, bladder cancer and triple-negative breast cancer. ${ }^{22-26}$ Enzalutamide (ENZ), also known as MDV-3100, is a novel FDA-approved AR antagonist which affects androgen signaling more effectively than other inhibitors. ${ }^{27}$ Kawahara et al showed that inhibition of AR using ENZ could effectively reduce AR-positive bladder cancer cell growth, migration, and invasion. ${ }^{22}$ They also assessed multiple anti-AR drugs in UMUC3 xenograft-bearing mice and demonstrated that only ENZ could significantly suppress the tumor growth. En masse, the present study aims at investigating the expression and prognostic role of $A R$ in GC patients, along with the assessment of the plausible correlation between its expression profile and overall survival of the patients. Moreover, this study examines the molecular mechanisms underlying the effects of AR inhibition using ENZ, either as a single agent or in combination with 5-FU, to propose a possible complex network in which AR signaling pathway could promote progression and metastasis of GC.

\section{Patients and Methods}

\section{Patients and Clinicopathological Data}

During June 2016 to June 2017, 75 newly diagnosed GC patients who referred to Kasra, Madaen, or Imam Khomeini hospitals, Tehran, Iran and experienced gastrectomy were entered in the study. Notably, patients without sufficient clinicopathological data and patients who were lost to follow-up, suffered from double primary tumors or received radiotherapy and/or chemotherapy before surgery were not included in this study. Amongst all patients, 60 fresh tumor tissues and adjacent nontumor tissue samples were used for further investigations. In addition, 50 fresh normal gastric samples were obtained from cases who had undergone endoscopy procedure at the Digestive Oncology Research Center, Digestive Diseases Research Institute, Shariati hospital, Tehran, Iran. For reliable gene expression analysis, all fresh samples were stabilized in RNA later solution (RNAlater RNA Stabilization Reagent, QIAGEN, Germany) within $15 \mathrm{~min}$ of excision. We regularly observed GC patients from the date of surgery until the end of our study period (May, 2020) or earlier in case of a patient's death due to cancer. This period of time was defined as overall survival (OS). Informed consents were signed by all patients. The present study committed to the principles of the Declaration of Helsinki 1964 as well as the Hematology, Oncology and Stem Cell Transplantation Research Institute, Shariati hospital, and approved by the Clinical Research Ethics Committee of Tehran University of Medical School with the approval code: ir.TUMS. horcsct.rec.1394.103.10.

\section{Human Gastric Cancer Cell Lines}

Three human GC cell lines (KATO III, AGS, and MKN45), and one prostate cancer cell line (LNCaP) were obtained from the National Cell Bank of Iran (NCBI; Tehran, Iran). CRL-5822 (NCI-N87), a human GC cell line was a generous gift from Avicenna Research Institute, ACECR, Tehran, Iran. KATO III, MKN45, and CRL-5822 were obtained from metastatic sites; in contrast, AGS is an adenocarcinoma cell line from the stomach. All the cell lines received from NCBI and also the gifted cells 
(CRL-5822) were authenticated by STR profiling (Cell ID $^{\text {TM }}$ system, Promega) and were routinely checked for mycoplasma infection using PCR and direct culture methods. GC cell lines were cultured according to ATCC recommendations and maintained at $37^{\circ} \mathrm{C}$ under humidified atmosphere with $5 \% \mathrm{CO}_{2}$.

\section{Chemicals and Antibodies}

Enzalutamide (MDV3100) and dihydrotestosterone (DHT) were purchased from Selleckchem (Houston, TX, USA) and were dissolved in DMSO. In all treatments, final concentrations of DMSO did not exceed $0.1 \%(\mathrm{v} / \mathrm{v})$. Monoclonal anticaspase- 3 and $\beta$-actin were obtained from Abcam, Mediqip; USA and Santa Cruz Biotechnology, respectively.

\section{Total RNA Preparation}

RiboEx reagent (GeneAll Biotechnology Co., South Korea) was used to extract total RNA from cell line lysates or the RNAlater-stabilized tissues. PrimeScriptTM RT reagent Kit (Takara, Japan) and an ABI Veriti Thermocycler (Applied Biosystems) were applied to synthesize complementary DNAs for $15 \mathrm{~min}$ at $37^{\circ} \mathrm{C}$, and five seconds at $85^{\circ} \mathrm{C}$.

\section{Reverse Transcription (RT) PCR}

Complementary DNAs (cDNAs) were amplified using specific primers. $B 2 M$ (beta-2-microglobulin) was used as a control gene. RT-PCR was performed using Taq DNA polymerase master mix red (Ampliqon, Copenhagen, Denmark) with ABI Veriti Thermocycler (Applied Biosystems). One percent agarose gel electrophoresis was applied to visualize the PCR products.

\section{Real-time Quantitative RT-PCR}

The quantitative RT-PCR (qRT-PCR) analysis was performed by LightCycler 96 instrument (Roche Molecular Diagnostics) using SYBRGreen RealQ-PCR Master Mix kit (Ampliqon, Copenhagen, Denmark) as instructed by the manufacturer. Water was used as negative control in the PCR reaction. Although three different housekeeping genes (B2M, HPRT, and GAPDH) were utilized for normalization, $B 2 M$ proved to be the most constant among the assessed genes with no variation between tissues. Therefore, $\Delta \mathrm{Ct}$ values were calculated to quantify mRNA expression levels by comparing it with the mean $\mathrm{Ct}$ values of $B 2 M$. The formula $2^{-(\Delta \Delta C T)}$ was used for calculations as described earlier. ${ }^{28}$ The sequences of all primers are listed in Supplemental Table 1.

\section{Cytotoxicity Assays}

KATO III, MKN45, CRL-5822, AGS and LNCaP cells in logarithmic growth phase were plated at a density of 2500 cells per well. Cell proliferation was assessed by MTT assay as previously described. ${ }^{29} \mathrm{IC}_{50}$ values were calculated from full dose-response curves to show cytotoxicity. Moreover, to determine the synergism of combinational treatment, MTT assay was applied after $72 \mathrm{~h}$ of treatment with ENZ plus fluorouracil (5-FU) or cisplatin in GC cells at the indicated concentrations. Combination index (CIx) and dose reduction index (DRI) were computed using Chou-Talalay method by CalcuSyn software (Biosoft, Cambridge, UK). CIx $<1$, CIx $=1$, and CIx $>1$ represent synergistic effects, additive effects, and antagonism of drugs, respectively. ${ }^{30}$

\section{Crystal Violet Staining}

Crystal violet staining assays were carried out as described earlier. $^{31}$

\section{Wound Healing Assays}

GC cells were cultured in six-well plates to reach about $100 \%$ confluency. After $24 \mathrm{~h}$, the cell monolayer was scratched with a pipette tip. After washing out the cells with PBS, they were treated with different concentrations of ENZ. Migration of the cells was assessed $48 \mathrm{~h}$ posttreatment under an inverted phase contrast microscope (Olympus).

\section{Zymography}

Briefly, equal amounts of the supernatants from the media of ENZ-treated and vehicle-treated cells were run on polyacrylamide gels copolymerized with gelatin A or B (Sigma). Gels were then rinsed in Triton X-100 to remove SDS, followed by incubation in reactivation buffer at $37^{\circ} \mathrm{C}$ overnight. Next, the gels were stained with Coomassie Brilliant Blue. Clear bands over the blue background showed the areas of enzymatic activity. ${ }^{31}$

\section{Cell Cycle Analysis}

The DNA contents of different steps of cell cycle were assessed with flow cytometry using propidium iodide (PI; $50 \mu \mathrm{g} / \mathrm{mL}$; Sigma) staining as explained previously. ${ }^{29}$ The samples were analyzed with a FACSCalibur (BD Bioscience) flow cytometer equipped with CellQuest Pro software. 
Table I Association Between AR Expression and Clinicopathological Characteristics of Patients with Gastric Cancer

\begin{tabular}{|c|c|c|c|c|}
\hline \multirow[t]{2}{*}{ Clinical Variables } & \multirow{2}{*}{$\begin{array}{l}\text { Total Patients: N (\%) } \\
60(100)\end{array}$} & \multicolumn{3}{|c|}{ Evaluable Patients: N (\%) } \\
\hline & & Overexpressed N (\%) & Underexpressed $\mathbf{N}(\%)$ & $\mathbf{P}$ \\
\hline Age (years) median, range & $63,33-83$ & & & \\
\hline$N<63$ & $29(48.3)$ & $18(30)$ & II (I8.3) & 0.465 \\
\hline$N \geq 63$ & $3 \mid(5 I .7)$ & $22(36.7)$ & $9(15)$ & \\
\hline \multicolumn{5}{|l|}{ Sex } \\
\hline Male & $39(65)$ & $26(43.3)$ & $13(21.7)$ & 1.000 \\
\hline Female & $21(35)$ & $14(23.3)$ & $7(11.7)$ & \\
\hline \multicolumn{5}{|l|}{ Tumor size $(\mathrm{cm})$} \\
\hline$N<5$ & $17(28.3)$ & $9(15)$ & $8(13.3)$ & 0.156 \\
\hline$N \geq 5$ & $43(71.7)$ & $31(5 \mid .7)$ & $12(20)$ & \\
\hline \multicolumn{5}{|l|}{ Lauren's classification } \\
\hline Intestinal & 55 (9I.7) & $36(60)$ & $19(31.7)$ & 0.656 \\
\hline Diffuse & $5(8.3)$ & $4(6.7)$ & $\mathrm{I}(\mathrm{I} .7)$ & \\
\hline \multicolumn{5}{|l|}{ Tumor grade } \\
\hline Poorly differentiated & $33(55)$ & $21(35)$ & $12(20)$ & \\
\hline Moderately differentiated & $21(35)$ & $15(25)$ & $6(10)$ & 0.919 \\
\hline Well differentiated & $6(10)$ & $4(6.7)$ & $2(3.3)$ & \\
\hline \multicolumn{5}{|l|}{ Tumor type } \\
\hline Adenocarcinoma & $46(76.7)$ & $29(48.3)$ & $17(28.3)$ & 0.347 \\
\hline Signet ring cell carcinoma & $14(23.3)$ & II (I8.3) & $3(5)$ & \\
\hline \multicolumn{5}{|l|}{ Lymphovascular invasion } \\
\hline Yes & $43(71.7)$ & $33(55)$ & $10(16.7)$ & $0.008^{*}$ \\
\hline No & $17(28.3)$ & 7 (II.7) & $10(16.7)$ & \\
\hline \multicolumn{5}{|l|}{ Perineural invasion } \\
\hline Yes & $50(83.3)$ & $33(55)$ & $17(28.3)$ & 1.000 \\
\hline No & $10(16.7)$ & $7(11.7)$ & $3(5)$ & \\
\hline \multicolumn{5}{|l|}{ Tumor shape } \\
\hline Ulcerated flat & $48(80)$ & $31(5 I .7)$ & $17(28.3)$ & \\
\hline Linitis plastica & $5(8.3)$ & $4(6.7)$ & $\mathrm{I}(\mathrm{I} .7)$ & 0.887 \\
\hline Polypoid & 7 (II.7) & $5(8.3)$ & $2(3.3)$ & \\
\hline \multicolumn{5}{|l|}{ Tumor location } \\
\hline Proximal & $28(46.7)$ & $17(28.3)$ & II (I8.3) & \\
\hline Middle & $22(36.7)$ & $15(25)$ & 7 (II.7) & 0.589 \\
\hline Distal & $6(10)$ & $4(6.7)$ & $2(3.3)$ & \\
\hline Diffuse & $4(6.7)$ & $4(6.7)$ & $0(0)$ & \\
\hline \multicolumn{5}{|l|}{ T classification ${ }^{\mathrm{a}}$} \\
\hline $\mathrm{pTl}$ & $0(0)$ & $0(0)$ & $0(0)$ & \\
\hline $\mathrm{pT} 2$ & $13(18.3)$ & $7(11.7)$ & $6(10)$ & $0.00 I^{*}$ \\
\hline pT3 & $19(31.7)$ & $8(13.3)$ & II (I8.3) & \\
\hline $\mathrm{pT} 4$ & $28(46.7)$ & $25(4 I .7)$ & $3(5)$ & \\
\hline \multicolumn{5}{|l|}{$\mathrm{N}$ classification ${ }^{\mathrm{a}}$} \\
\hline No & $19(31.7)$ & $8(13.3)$ & II (I8.3) & \\
\hline $\mathrm{NI}$ & II (18.3) & 7 (II.7) & $4(6.7)$ & $0.002 *$ \\
\hline N2 & $17(28.3)$ & $15(25)$ & $2(3.3)$ & \\
\hline
\end{tabular}


Table I (Continued).

\begin{tabular}{|l|l|l|l|l|}
\hline \multirow{2}{*}{ Clinical Variables } & Total Patients: N (\%) & \multicolumn{2}{|l|}{ Evaluable Patients: N (\%) } & \multicolumn{2}{l|}{} \\
\cline { 2 - 5 } & $\mathbf{6 0}(\mathbf{1 0 0})$ & Overexpressed N (\%) & Underexpressed N (\%) & P \\
\hline N3 & $13(21.7)$ & $10(16.7)$ & $3(5)$ & \\
\hline M classification & & & \\
M0 & & & $18(30)$ & $0.019 *$ \\
MI & $42(70)$ & $24(40)$ & $2(3.3)$ & \\
\hline TNM stage & $18(30)$ & $16(26.7)$ & $12(20)$ & \\
I+II & & $10(16.7)$ & $8(13.3)$ & $0.008^{*}$ \\
III+IV & $22(36.7)$ & $30(50)$ & $38(63.3)$ &
\end{tabular}

Notes: ${ }^{a}$ The 8th TNM Classification of Malignant Tumors proposed by the AJCC/UICC. $* P<0.05$ values are statistically significant.

Abbreviation: AR, androgen receptor.

\section{Flow Cytometric Analysis of Apoptosis}

To evaluate the apoptotic effect of ENZ on GC cells, PI and FITC-conjugated Annexin V Staining Kit (Roche Applied Science, Germany) was used for detection by flow cytometry. The results were analyzed using a Partec PAS III flow cytometer and TM FloMax software (Partec).

\section{Western Blot Analysis}

GC Cell lysates were assayed for protein concentration using the BCA Protein Assay Reagent kit (Thermo Scientific, USA). Proteins were resolved on SDS-PAGE and transferred to a PVDF membrane (Roche, Germany). After blocking the nonspecific binding sites with 5\% skim milk, the membrane was blotted with the human reactive monoclonal anti-caspase-3 (Abcam, USA) followed by incubation with the horseradish peroxidase conjugated secondary antibody (1:1000). Bound antibodies were detected with the ECL Western Blotting Detection System (GE Healthcare, UK). Hybridization with the $\beta$ actin was used as the loading control.

\section{Statistical Analysis}

Independent samples Mann-Whitney $U$-test was used to compare the difference in expression of AR and EMTrelated genes between gastric tumors and adjacent uninvolved tissues or normal tissues. Correlations between the genes were assessed by the Spearman rank test. Chisquared or Fisher's exact tests were applied to investigate the associations between expression of AR and EMTrelated genes and clinicopathological data. The expectation of survival was estimated by Kaplan-Meier (log rank test) method. For identification of the prognostic value of AR expression and other variables, univariate and multivariate Cox proportional hazards model was performed. All significant variables in the univariate analysis as well as clinical characteristics considered correlated with prognosis including age and tumor grade were entered to multivariate analysis. Stepwise backward elimination as a reduced model was performed until only significant factors remained in multivariate analysis. Two-tailed Student's $t$-test was used to analyze the data of functional experiments. The presented results are the means \pm SD of three independent experiments. The IBM SPSS ${ }^{\circledR}$ statistics 22 software and GraphPad Prism Software 8 were employed to perform statistical analysis. Two-tailed $P<0.05$ was considered statistically significant.

\section{Results \\ Clinicopathological Characteristics}

To assess the expression level of $A R$ and to explore its plausible contributory role in GC, both the fresh tumor and the adjacent nontumor tissues of $60 \mathrm{GC}$ patients were included in the study. Clinicopathological characteristics of patients with GC, including sex, age, tumor size, tumor grade, tumor type, Lauren's classification, lymphovascular and nerve invasion, tumor shape, tumor location, TNM classification and disease stages, were enrolled as listed in Table 1 . Fifty normal cases ( 25 female, 25 male) with median age of 51 ranging from 19 to 83 were also included for comparison. Among GC patients, 66.7\% (40/60) overexpressed AR relative to normal samples. Possible relationship between clinicopathological characteristics and AR expression was analyzed and notably, significant statistical correlation was detected between $\mathrm{AR}$ overexpression and lymphovascular invasion, $\mathrm{T}$ classification, $\mathrm{N}$ classification, and $\mathrm{M}$ classification. Importantly, overexpression of AR was 


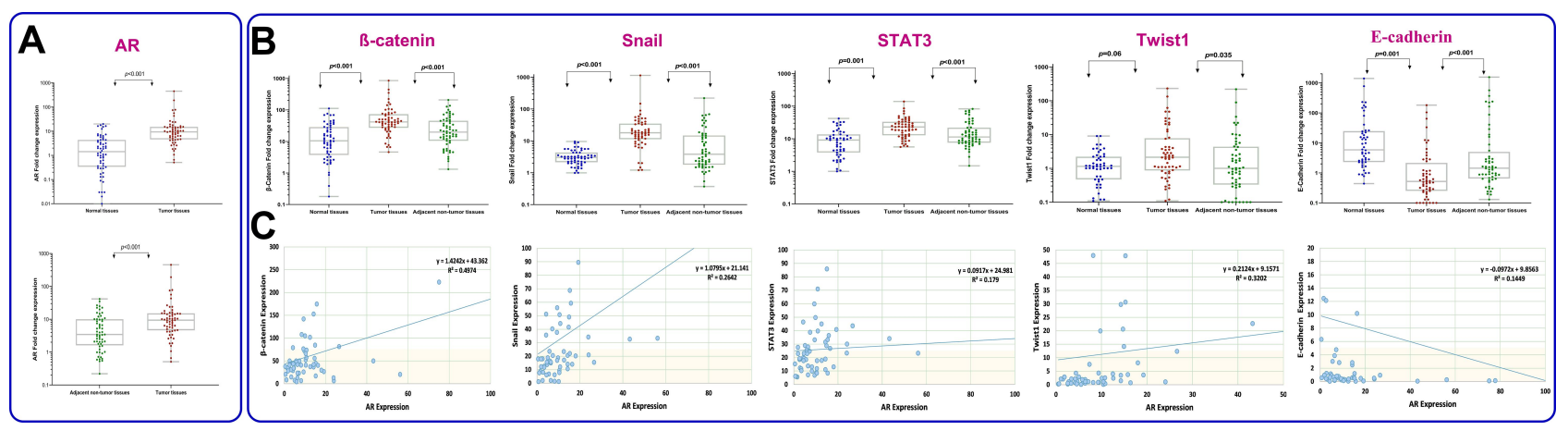

Figure I Graphical box-plot expression profile of (A) AR, (B) $\beta$-catenin, Snail, STAT3, Twistl and E-cadherin at transcriptome level in gastric tumor, adjacent nontumor $(\mathrm{N}=60)$ and normal tissues $(\mathrm{N}=50)$. Results are the mean of three independent experiments $\pm S D(P<0.05)$. (C) Correlation between AR and EMT-related gene expression analyzed by Spearman rank test.

more frequently found in patients with advanced TNM stages $(P=0.008)$. When age and gender is concerned, no remarkable association was found.

\section{Overexpression of $A R$ is Correlated with the Expression of EMT-related Genes in Gastric Cancer}

Quantitative real-time PCR was applied to detect the mRNA expression levels of $A R, \beta$-catenin, E-cadherin,
Snail, Twist1 and STAT3 in gastric tumor, adjacent uninvolved tissues, and normal cases.

In the present study, one of the normal samples with the highest $\mathrm{Ct}$ value was considered as a calibrator for each specific gene. To calculate the fold change of gene expression all other samples were compared with the specific calibrator. Thereafter, we used ROC curve to determine the cutoff value of the genes. The values which were higher than cutoff point were defined as overexpression. As shown in Figure 1A and B, the relative mRNA expression values of $A R, \beta$-catenin, Snail,

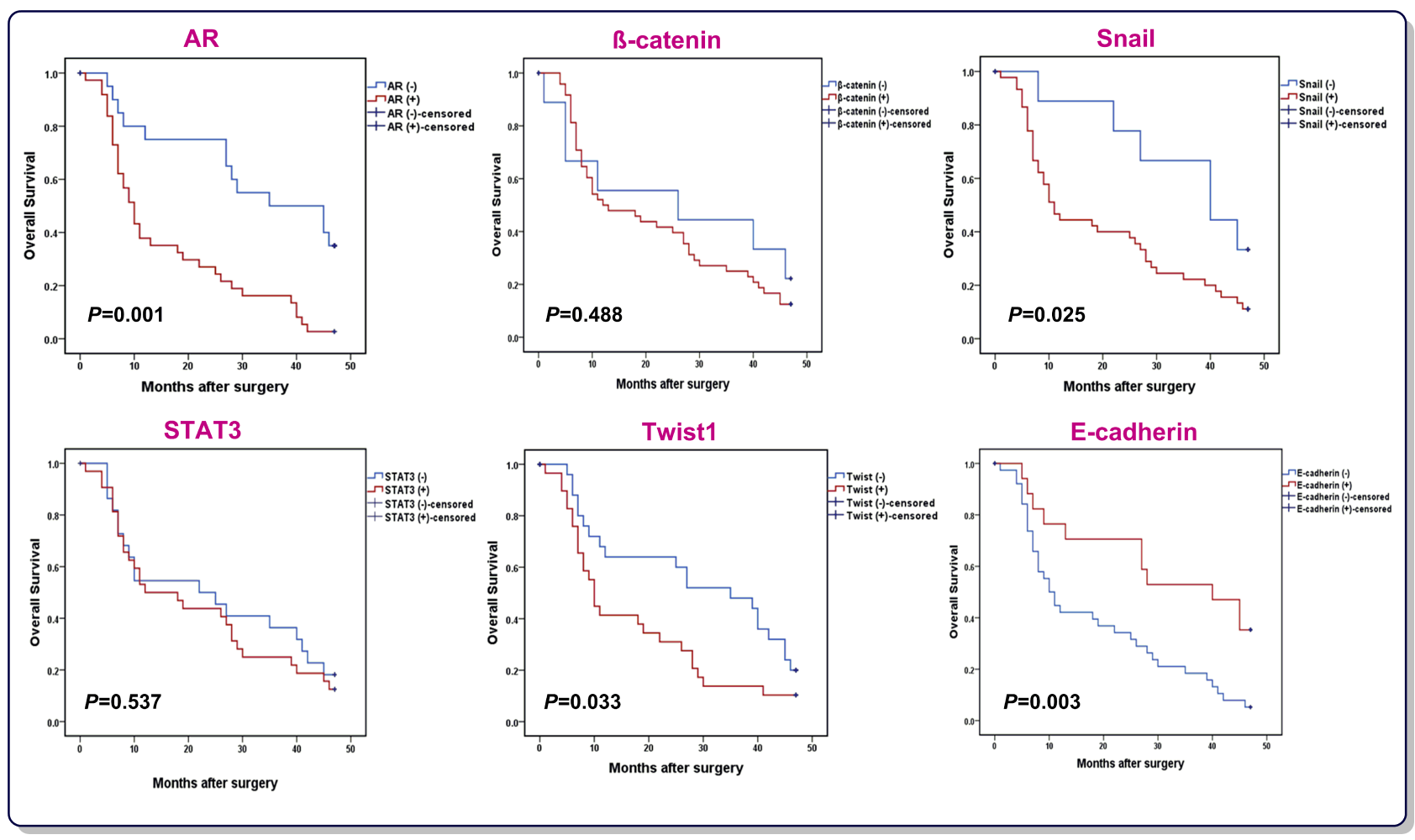

Figure 2 Kaplan-Meier curves of OS for GC patients ( $N=57$ ) according to AR, $\beta$-catenin, Snail, STAT3, Twistl and E-cadherin expression (log rank test). 
Table 2 Univariate and Multivariate Cox Regression Analysis of Overall Survival in Patients with Gastric Cancer

\begin{tabular}{|c|c|c|c|c|c|c|}
\hline \multirow[t]{2}{*}{ Variables } & \multicolumn{3}{|c|}{ Univariate Cox } & \multicolumn{3}{|c|}{ Multivariate Cox } \\
\hline & HR & $95 \% \mathrm{Cl}$ & $P$ & HR & $95 \% \mathrm{Cl}$ & $P$ \\
\hline \multicolumn{7}{|l|}{ Sex } \\
\hline Male & 1.000 & & & & & \\
\hline Female & 0.785 & $0.388-1.59 \mid$ & 0.636 & & & \\
\hline \multicolumn{7}{|l|}{ Age (years) median, range } \\
\hline $\mathrm{n}<63$ & 1.000 & & & 1.000 & & \\
\hline$n \geq 63$ & 1.364 & $0.693-2.133$ & 0.346 & 1.000 & $0.249-1.967$ & 0.499 \\
\hline \multicolumn{7}{|l|}{ Tumor size $(\mathrm{cm})$} \\
\hline $\mathrm{n}<5$ & 1.000 & & & 1.000 & & \\
\hline$n \geq 5$ & 2.670 & 1.309-5.447 & $0.007 *$ & 1.625 & $0.841-3.702$ & 0.254 \\
\hline \multicolumn{7}{|l|}{ Lauren's classification } \\
\hline Intestinal & 1.000 & & & & & \\
\hline Diffuse & 2.452 & $0.74 I-8.112$ & 0. 142 & & & \\
\hline \multicolumn{7}{|l|}{ Tumor grade } \\
\hline Well differentiated & 1.000 & & & & & \\
\hline Moderately differentiated & 1.269 & $0.272-5.150$ & 0.822 & & & \\
\hline Poorly differentiated & 1.337 & $0.296-6.040$ & 0.705 & & & \\
\hline \multicolumn{7}{|l|}{ Lymphovascular invasion } \\
\hline No & 1.000 & & & 1.000 & & \\
\hline Yes & 2.619 & $1.280-6.759$ & $0.008 *$ & 2.096 & $0.387-2.312$ & 0.763 \\
\hline \multicolumn{7}{|l|}{ Perineural invasion } \\
\hline No & 1.000 & & & 1.000 & & \\
\hline Yes & 2.540 & $1.006-6.460$ & $0.050 *$ & 1.346 & $0.214-3.345$ & 0.866 \\
\hline \multicolumn{7}{|l|}{ T classification ${ }^{\mathrm{a}}$} \\
\hline PTI & & & & & & \\
\hline PT2 & 1.000 & & & 1.000 & & \\
\hline $\mathrm{PT} 3$ & 2.523 & $1.000-6.480$ & $0.050 *$ & 3. 252 & $0.934-11.822$ & 0.064 \\
\hline PT4 & 4.955 & $1.971-12.374$ & $0.001 *$ & 3.724 & $1.155-12.005$ & $0.028 *$ \\
\hline \multicolumn{7}{|l|}{$N$ classification ${ }^{\mathrm{a}}$} \\
\hline No & 1.000 & & & 1.000 & & \\
\hline $\mathrm{NI}$ & 2.479 & $1.268-5.886$ & $0.04 I^{*}$ & 2.846 & $0.980-8.341$ & 0.055 \\
\hline N2 & 6.306 & $2.680-15.573$ & $0.001 *$ & 4.958 & $1.319-14.832$ & $0.003 *$ \\
\hline N3 & 8.801 & $3.36 I-22.104$ & $0.001 *$ & 11.614 & $3.419-38.832$ & $0.001 *$ \\
\hline \multicolumn{7}{|l|}{ M classification ${ }^{\mathrm{a}}$} \\
\hline Mo & 1.000 & & & 1.000 & & \\
\hline MI & 3.353 & $|.709-6.47|$ & $0.002 *$ & 3.947 & $1.733-9.389$ & $0.001 *$ \\
\hline \multicolumn{7}{|l|}{ TNM stage ${ }^{a}$} \\
\hline I+II & 1.000 & & & & & \\
\hline III+IV & 19.259 & $5.579-66.411$ & $0.001 *$ & & & \\
\hline \multicolumn{7}{|l|}{ AR } \\
\hline Underexpressed & 1.000 & & & 1.000 & & \\
\hline Overexpressed & 3.478 & $1.580-8.768$ & $0.001 *$ & 2.089 & $0.998-4.643$ & 0.056 \\
\hline \multicolumn{7}{|l|}{$\beta$-catenin } \\
\hline Underexpressed & 1.000 & & & & & \\
\hline Overexpressed & 1.321 & $0.437-3.564$ & 0.499 & & & \\
\hline
\end{tabular}

(Continued) 
Table 2 (Continued).

\begin{tabular}{|c|c|c|c|c|c|c|}
\hline \multirow[t]{2}{*}{ Variables } & \multicolumn{3}{|c|}{ Univariate Cox } & \multicolumn{3}{|c|}{ Multivariate Cox } \\
\hline & HR & $95 \% \mathrm{Cl}$ & $P$ & HR & $95 \% \mathrm{Cl}$ & $P$ \\
\hline \multicolumn{7}{|l|}{ E-cadherin } \\
\hline Underexpressed & 1.000 & & & 1.000 & & \\
\hline Overexpressed & 0.372 & $0.139-0.982$ & $0.005 *$ & 0.665 & $0.280-1.158$ & 0.355 \\
\hline \multicolumn{7}{|l|}{ Snail } \\
\hline Underexpressed & 1.000 & & & 1.000 & & \\
\hline Overexpressed & 3.618 & $1.028-10.406$ & $0.046 *$ & 2.152 & $0.974-6.100$ & 0.084 \\
\hline \multicolumn{7}{|l|}{ Twist } \\
\hline Underexpressed & 1.000 & & & 1.000 & & \\
\hline Overexpressed & 1.865 & $1.005-4.629$ & $0.040 *$ & 1.001 & $0.310-1.444$ & 0.279 \\
\hline \multicolumn{7}{|l|}{ Stat3 } \\
\hline Underexpressed & 1.000 & & & & & \\
\hline Overexpressed & 1.259 & $0.504-2.446$ & 0.564 & & & \\
\hline
\end{tabular}

Notes: ${ }^{a}$ The 8th TNM Classification of Malignant Tumors proposed by the AJCC/UICC. $* P<0.05$ values are statistically significant.

Abbreviations: $\mathrm{HR}$, hazard ratio; $\mathrm{Cl}$, confidence interval; $\mathrm{AR}$, androgen receptor.

Twist 1 and STAT3 in GC tissues were significantly higher than those in adjacent nontumor tissues (median expression of $A R$, 9.39 vs $3.44, P<0.001 ; \beta$-catenin, 41.59 vs $19.91, P<0.000$; Snail, 17.95 vs 3.81, $P<0.000$; Twist1, 2.1 vs $1.02, P<0.035$; STAT3, 23.1 vs 11.3, $P<0.001$ ). In contrast, the expression of E-cadherin in GC tissues was significantly lower than adjacent nontumor tissues $(0.52$ vs $1.44, P<0.001)$. A similar pattern was also detected when tumor tissues were compared to normal cases (Figure 1); however, the relative mRNA expression difference of Twist 1 was not statistically significant. Spearman rank test was used to assess correlation between mRNA expression of $A R$ and EMT-related genes selected in this study (Figure $1 \mathrm{C}$ ). While there was a strong positive correlation between $A R$ and $\beta$-catenin ( $\mathrm{r}=0.705, P=0.004)$, a negative correlation was detected between $A R$ and E-cadherin ( $\mathrm{r}=$ $-0.385, P=0.003$ ). Notably, correlation coefficients showed that $A R$ expression moderately correlates with Snail, Twist1 and STAT3 (r=0.512, $P<0.001 ; \mathrm{r}=0.560, P<0.001$ and $\mathrm{r}=0.424$, $P=0.001$ respectively).

\section{AR, Snail, Twist I and E-cadherin Expressions Correlate with an Unfavorable Outcome in GC Patients}

Having established that AR, $\beta$-catenin, Snail, Twist1, and STAT3 were upregulated in GC patients, it was tempting to investigate if there is any correlation between the expressions of the aforementioned genes and GC patients OS. All 60 patients were followed-up and then prognostic values of genes were analyzed using Kaplan-Meier method (Figure 2).
The rate of OS for patients overexpressing $A R$ was $10 \%$ (4/40) in comparison with $35 \%(7 / 20)$ for patients underexpressing $A R(P=0.001)$. Moreover, while both the overexpression of Snail and Twist 1 and the underexpression of E-cadherin were found to be unfavorable prognostic factors, other mentioned genes had no remarkable correlation with OS. The univariate and multivariate analysis data from Cox proportional hazards model is reported in Table 2. Regarding the univariate analysis, the tumor size, lymphovascular invasion, perineural invasion, $\mathrm{T}$ classification, $\mathrm{N}$ classification, $\mathrm{M}$ classification, TNM stage, AR expression, Snail expression, Twist 1 expression and E-cadherin expression were found to be significant prognostic factors; however, only T, N, and M classifications maintained in the multivariate Cox regression model, indicating that the expression of AR, Snail, E-cadherinand Twist 1 were not independent unfavorable factors for OS in GC patients. Of particular interest, Kaplan-Meier analysis indicated higher mortality rate among GC patients who simultaneously overexpressed $A R$ and Snail (HR=3.236, 95\%CI=1.688-6.205, $P=0.001$ ). Therefore, concurrent overexpression of $A R$ and Snail genes, as a single variable, disclosed to be an independent unfavorable factor for OS adjusted for other variables using multivariate Cox regression model $(\mathrm{HR}=2.382,95 \%$ $\mathrm{CI}=1.141-4.971, P=0.021)$.

\section{Inhibition of AR Signaling Suppresses the Proliferation of GC Cell Lines}

Based on increased expression of $A R$ as well as significant correlation of this receptor with an unfavorable outcome in 


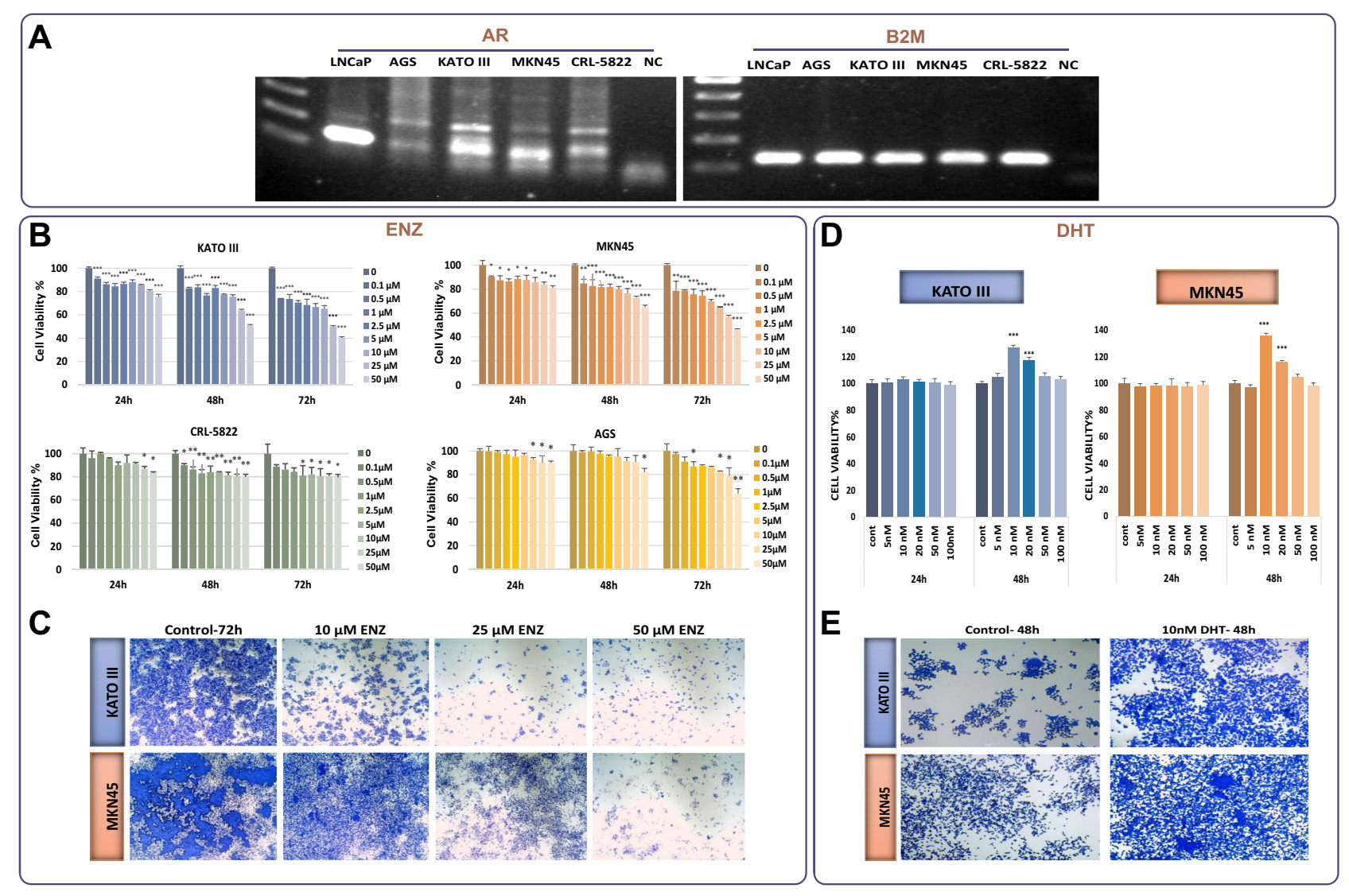

Figure 3 The anticancer effects of ENZ on GC cell lines. (A) Basal level of AR mRNA expression in four gastric cancer cell lines and LNCaP cells detected by RT-PCR. Digital images of the gels were captured using a Bio-Rad gel documentation system using Image Lab Software. The samples derived from the same Gel. Our desired AR band is at 105 bp. Nonspecific bands disappeared after optimizing PCR condition and increasing the annealing temperature in conventional PCR. (B) The effect of ENZ on proliferation of GC cells and LNCaP cells was determined by MTT assay 24,48 , and $72 \mathrm{~h}$ posttreatment. Data are given as mean \pm SD. (C) The effects of ENZ on GC cell viability were demonstrated by crystal violet staining $72 \mathrm{~h}$ posttreatment. The cultures were stained with crystal violet and imaged by an inverted microscope (images acquired at $4 \times$ magnification). (D) The effect of DHT (nM) on proliferation of GC cells was determined by MTT assay 24,48 , and $72 \mathrm{~h}$ posttreatment. Data are given as mean $\pm S D$. (E) The effects of DHT on GC cell viability were demonstrated by crystal violet staining $48 \mathrm{~h}$ posttreatment. Statistically significant values of $* P<0.05$, $* * P<0.0 \mathrm{I}$, and $* * * P<0.001$ were determined compared with the control.

GC patients, it was reasonable to investigate the effect of AR inhibition on GC cell lines. First we used conventional PCR to examine the basal mRNA expression level of $A R$ in four gastric cancer cell lines and LNCaP cells, as an AR-positive cell line. ${ }^{32}$ While all the tested GC cell lines expressed $A R$, we found that $A R$ expression levels in MKN45 and KATO III cells were higher than AGS and CRL-5822 (Figure 3A). Accordingly, when GC cell lines were exposed to the increasing concentrations (0.1-50 $\mu \mathrm{M})$ of a novel AR antagonist enzalutamide (ENZ), ${ }^{27}$ the survival of all tested cells were decreased in concentrationand time-dependent manners (Figure 3B). It is worth mentioning that KATO III and MKN45 cells were more sensitive to the inhibitor compared to AGS and CRL-5822 cells harboring lower amount of the receptor.
Based on the prominent cytotoxicity of ENZ on KATO III and MKN45, further experiments were expanded on these cell lines. As presented in Figure $3 \mathrm{C}$, the results of crystal violet staining assay showed that the inhibition of AR could decrease the proliferation of KATO III and MKN45 cells both in time- and concentration-dependent manners. To validate our results, we assessed the effect of AR activation on $\mathrm{GC}$ cells proliferation upon treatment of the cells using a potent AR agonist dihydrotestosterone (DHT). Consistent with the results achieved upon treatment of the cells with ENZ, we found that not only had the activation of AR significantly increased cell viability after $48 \mathrm{~h}$, but it also promoted cancer cell proliferation both in KATO III and MKN45 cells (Figure 3D and E). 


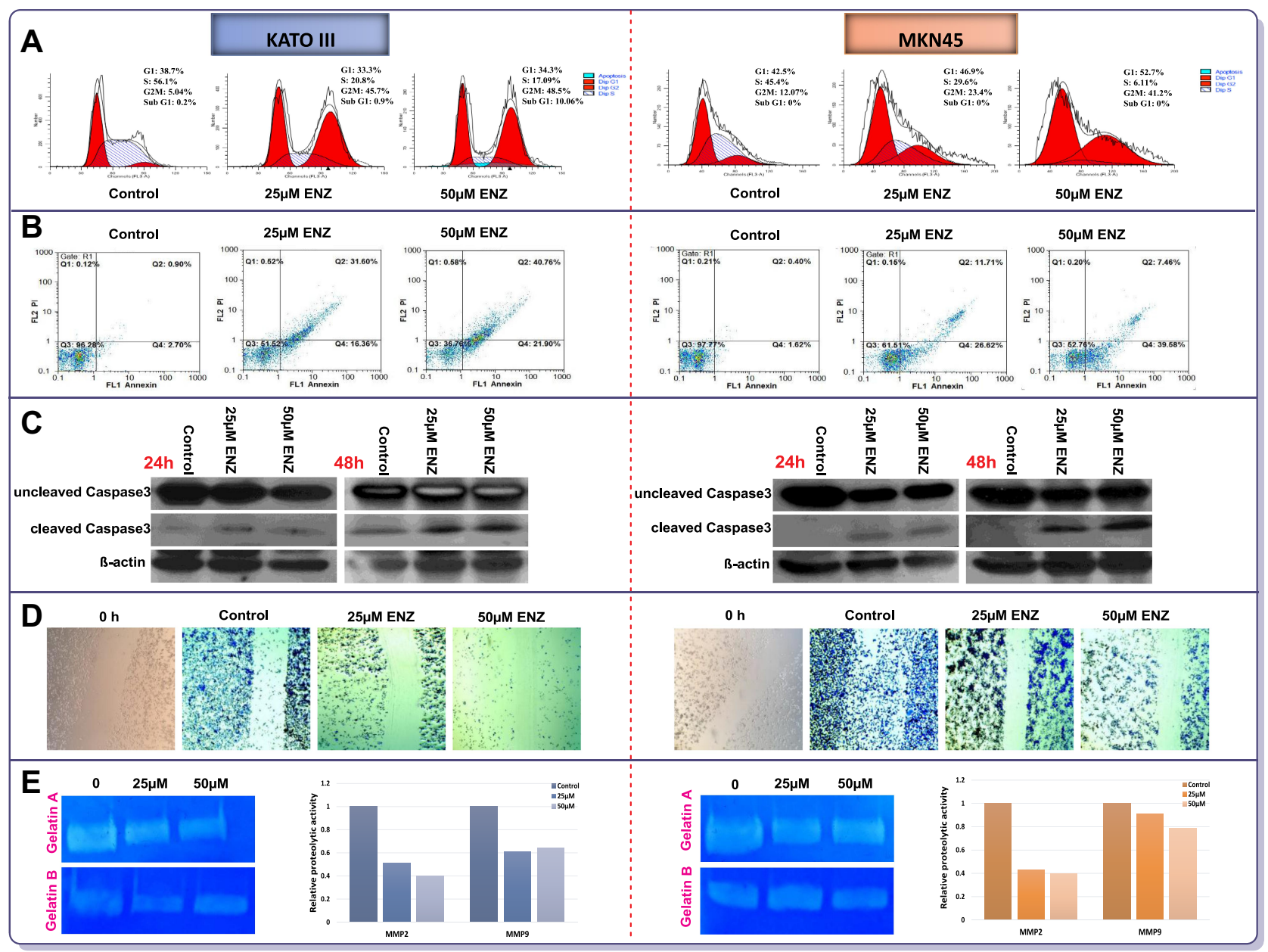

Figure 4 The effects of ENZ on induction of (A) Cell cycle arrest and (B) Apoptosis in GC cell lines 48 h posttreatment. The flow cytometry graphs of cell cycle and apoptosis are representative of three independent experiments with similar outcomes. The effects of ENZ (25 and $50 \mu \mathrm{M})$ on activation of caspase-3 (cleaved form) in GC cells were determined by Western blot analysis, 24 and $48 \mathrm{~h}$ posttreatment $(\mathbf{C})$. The blots are representative of three independent experiments with similar outcomes. $\beta$ actin was used as loading control. The effects of ENZ on migration and metastasis of GC cell lines (D) Representative pictures of wound healing scratch assays of vehicle and ENZ treated cells (images acquired at 10x magnification). (E) Representative gelatin zymogram showing MMP9 and MMP2 activities in ENZ treated cells after 48 h. Gelatinolytic activities are visualized as clear bands against the blue background of stained gelatin and the intensity of each band was quantified by GelQuant.net.

\section{Antiproliferative, Apoptotic, and}

\section{Antimetastatic Effects of AR Inhibition on KATO III and MKN45 GC Cells}

In the light of the antiproliferative effect of AR inhibition on $\mathrm{GC}$ cell lines and to explore the potential mechanism of action of the inhibitor, we assessed both the cell cycle pattern and apoptosis induction using flow cytometry. As shown in Figure 4A, while untreated KATO III and MKN45 cells were mainly in S phase, $48 \mathrm{~h}$ treatment with ENZ resulted in a remarkable decrease in the fraction of S phase as well as the induction of G2/M cell cycle arrest in both cell lines. Our data also revealed that the percentage of apoptotic dead cells was robustly increased in the cultures of the cells treated with the inhibitor in a concentration-dependent manner (Figure 4B). We next examined the level of a key enzyme involved in apoptosis, caspase-3, in GC cells, 24 and $48 \mathrm{~h}$ posttreatment with ENZ (Figure 4C). ENZ significantly induced cleaved caspase- 3 in a time- and dose-dependent manner in both GC cell lines. Evidences indicated that AR could contribute in the invasion of tumor cells through the induction of MMP-2 and MMP-9 enzymatic levels. ${ }^{1,33}$ As depicted in Figure 4D, ENZ at the concentrations of $25 \mu \mathrm{M}$ and $50 \mu \mathrm{M}$ significantly inhibited cell migration in both KATO III and MKN45 cell lines, compared with the vehicle-treated cells. In agreement with wound healing assay, we found that ENZ clearly reduced both MMP-2 and MMP-9 activities in GC cell lines $48 \mathrm{~h}$ posttreatment (Figure 4E). Intensities of clear bands demonstrated the diminishing gelatinolytic activities of MMP2 and MMP9 against the blue background of the stained gelatin. 


\section{AR Signaling Targets the EMT-related Genes Transcription in GC Cells}

To delve into the molecular mechanisms by which AR inhibition could either induce apoptosis or suppress cell cycle progression in $\mathrm{GC}$ cells, we aimed to analyze the mRNA expression levels of apoptosis- and cell cyclerelated genes using real-time PCR. In addition, molecular analysis of genes involved in epithelial-mesenchymal transition (EMT) was also examined to shed more light on the suppressive effect of the inhibitor on the invasive ability of KATO III and MKN45. As presented in Figure 5, not only could ENZ significantly alter pro- and anti-apoptotic genes, but it also induce its growth suppressive effect through a p21-mediated $\mathrm{G} 2 / \mathrm{M}$ arrest in both $\mathrm{GC}$ cell lines. Intriguingly, our data showed that the mRNA expression of $\beta$-catenin, Snail, Twist1, and STAT3 were significantly diminished, while the mRNA level E-cadherin was upregulated upon treatment with ENZ. A similar pattern was also observed in MKN45 cells, except for the expression of Twist 1 which did not remarkably vary in this cell line (Figure 5).

\section{Stimulatory Effect of Enzalutamide on 5- Fluorouracil Cytotoxicity on GC Cell Lines}

Given the frequent acquisition of chemoresistant phenotype in $\mathrm{GC}^{34}$ as well as the proven effect of ENZ on metastatic castration-resistant prostate cancer (mCRPC), ${ }^{35}$ we wondered if the inhibition of AR signaling may achieve higher cytotoxicity with 5-fluorouracil (5$\mathrm{FU}$ ) as one of the most effective chemotherapy drugs used in GC patients. Notably, combination of ENZ with 5-FU clearly displayed a synergistic effect on cell survival in both GC cell lines. As presented in Figure 6A, normalized isobolograms of combination of AR inhibitor (25 and 50 $\mu \mathrm{M})$ and 5 -FU $(0.1,0.5,1,2.5$, and $5 \mu \mathrm{M})$ revealed that all

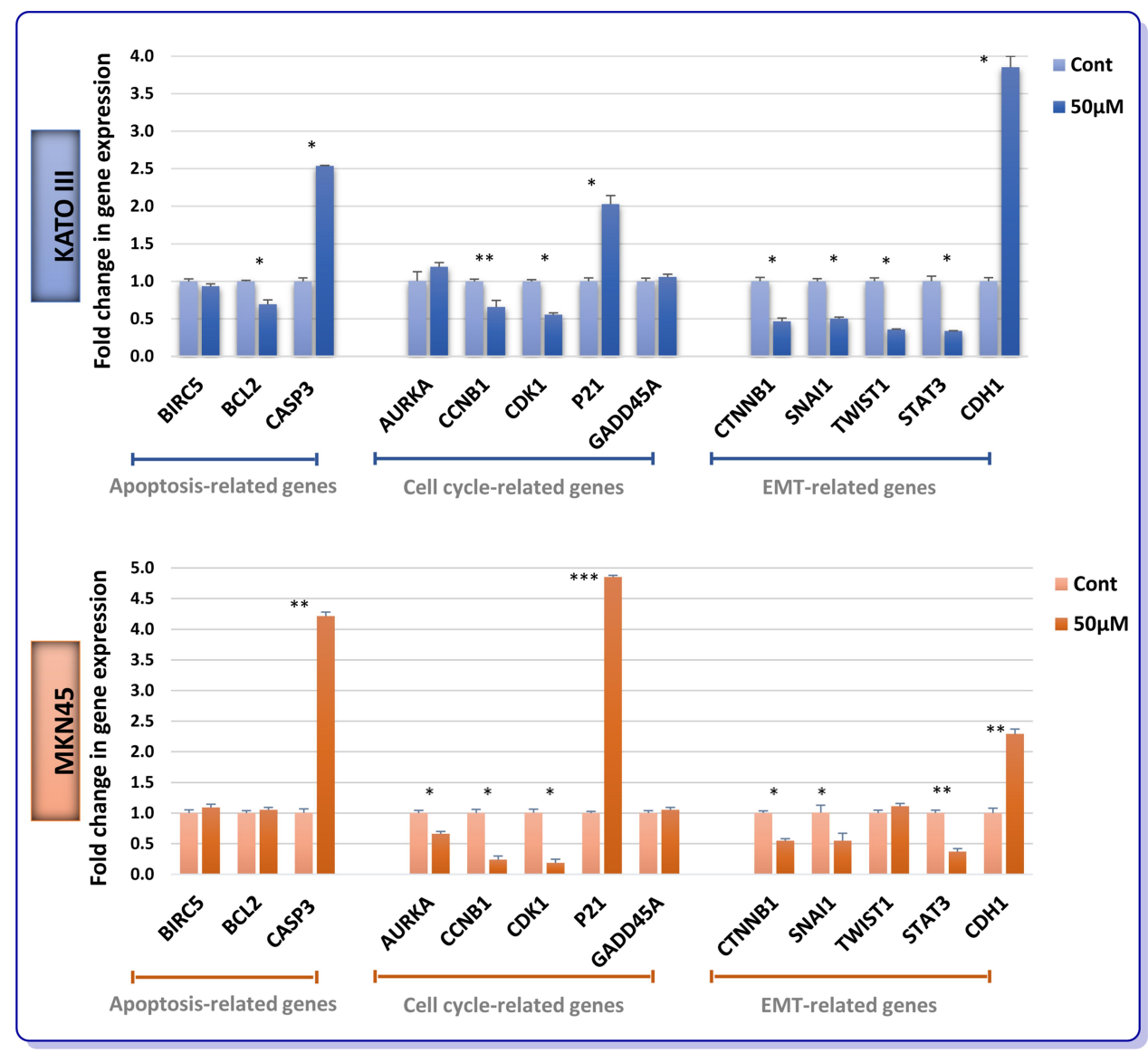

Figure 5 Effect of ENZ on apoptosis, cell cycle and EMT-related genes expression. After $48 \mathrm{~h}$ treatment with ENZ (50 $\mu M)$, the GC cells were harvested for quantitative real-time PCR test. Gene expression levels were normalized to $B 2 M$. Data are given as mean $\pm S D$. Statistically significant values of $* P<0.05$, $* * P<0.01$, and $* * * P<0.00 I$ were determined compared with the control.

Abbreviations: BIRC5, survivin; CASP3, caspase-3; AURKA, aurora kinase A; CCNBI, cyclin BI; CDKI, cyclin-dependent kinase I; GADD45A, growth arrest and DNA damage inducible alpha. 


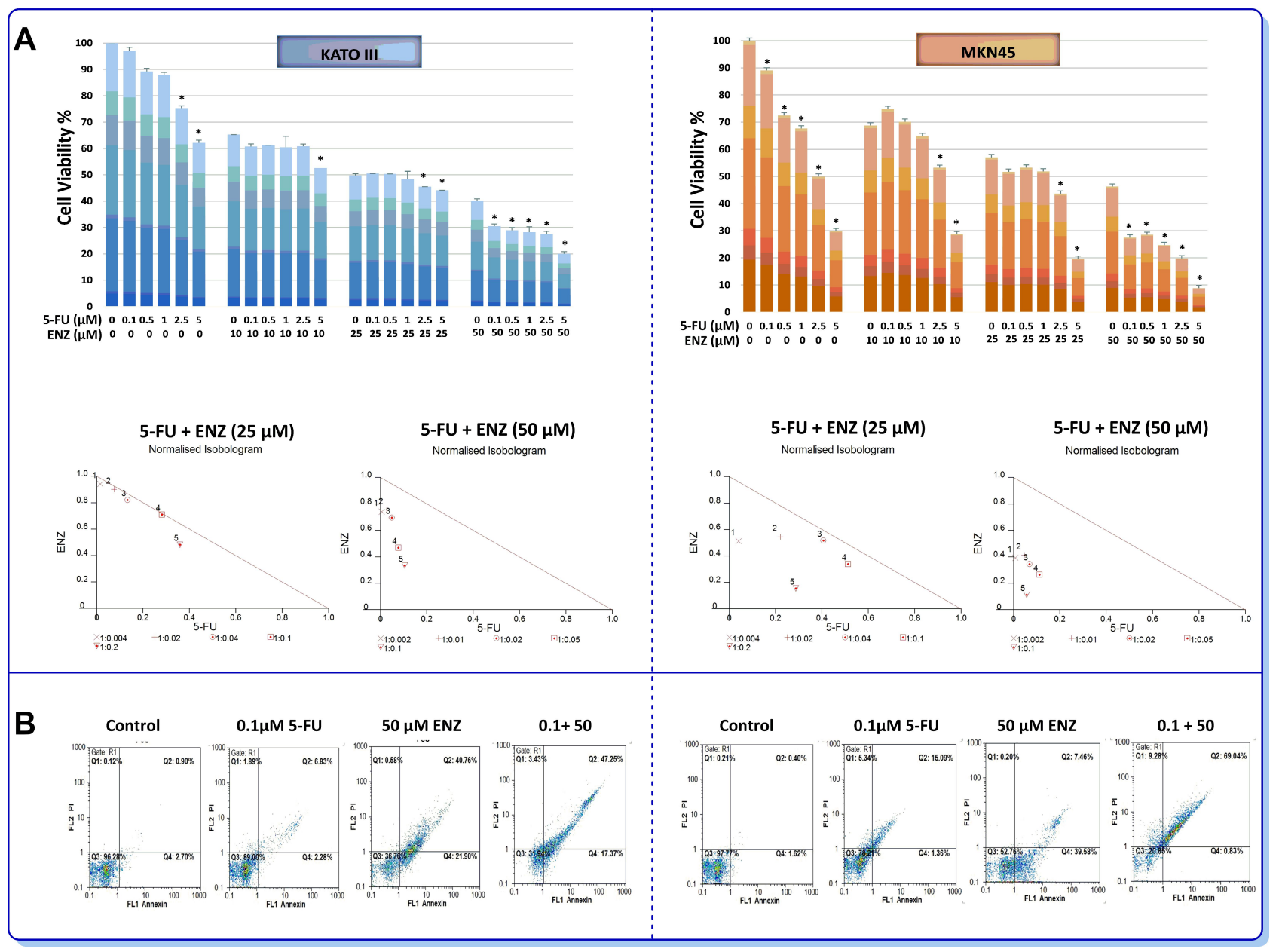

Figure 6 Synergistic activity of 5-fluorouracil with ENZ-targeted therapy (A) AR inhibiting enhances sensitivity to 5-FU in GC cells. The effects of ENZ in combination with 5 -FU on cell proliferation were investigated by MTT assay $72 \mathrm{~h}$ posttreatment. In normalized isobolograms of combination of ENZ (I0, $25,50 \mu \mathrm{M})$ and 5 -FU ( $0 . \mathrm{I}, 0.5, \mathrm{I}, 2.5$, and $5 \mu \mathrm{M}$ ), the connecting line represents additivity. Data points located below the line indicate a synergistic drug-drug interaction and data points above the line indicate an antagonistic drug-drug interaction. Statistically significant values of $* P<0.05$ were determined compared with the control. (B) The combinatory effects of ENZ and 5 -FU to induce apoptosis in GC cells assessing by flow cytometry. The apoptosis graphs are representative of three independent experiments with similar outcomes.

the points are located below the line of additive effect. Combination index (CIx) and dose reduction index (DRI) of ENZ and 5-FU in GC cells are presented in Table 3. Stimulatory effect of AR inhibition on the cytotoxic effect of 5-FU against GC cell lines was further validated using flow cytometric analysis of annexin-V/PI assay. As presented in Figure 6B, we found that 5-FU in combinational treatment induced apoptosis more than single agent therapy in GC cells, as the percentage of apoptotic dead cells was remarkably higher in the cultures of the cells cotreated with ENZ and 5-FU.

\section{Discussion}

Men develop GC more than women. ${ }^{3}$ Clarifying the factors that cause gender disparity of GC may help to disclose underlying molecular pathways in gastric carcinogenesis.
There are several studies indicating AR as an oncoprotein involved in tumor growth, progression and metastasis in male-predominant cancers. ${ }^{12,14,15}$ Although GC belongs to this family, few studies have investigated the role of AR in GC prognosis leading to conflicting results. The results obtained in the present study demonstrate that $66.7 \%$ of GC patients overexpressed $A R$ relative to normal cases. We also found that the higher expression rate of $A R$ is positively associated with higher lymphovascular involvement rate, increased risk of lymph node metastasis, larger tumor mass, more distant metastasis, and subsequently late TNM stages; shedding light on the fact that AR probably plays an important role in the progression and late-stage carcinogenesis of GC. Not only have many studies revealed that dysregulation of EMT is a prevalent phenomenon in GC, ${ }^{36-39}$ but also it has been frequently reported 
Table 3 Combination Index $(\mathrm{Clx})$ and Dose Reduction Index (DRI) of ENZ and 5-FU Combination in MKN45 and KATO III Cells.

\begin{tabular}{|c|c|c|c|c|c|}
\hline \multicolumn{2}{|c|}{ Concentrations $(\mu \mathrm{M})$} & \multirow[t]{2}{*}{ fa } & \multirow[t]{2}{*}{ Clx } & \multicolumn{2}{|l|}{ DRI } \\
\hline ENZ & 5-FU & & & ENZ & 5-FU \\
\hline \multicolumn{6}{|l|}{ KATO III } \\
\hline 10 & 0.1 & $0.24 I$ & 0.947 & 1.107 & 23.149 \\
\hline 10 & 0.5 & 0.248 & 1.07 & 1.156 & 4.87 \\
\hline 10 & I & 0.325 & 0.808 & 1.785 & 4.034 \\
\hline 10 & 2.5 & $0.34 I$ & 1.079 & 1.939 & $\mathrm{I} .777$ \\
\hline 10 & 5 & 0.413 & 1.11 & 2.758 & 1.339 \\
\hline 25 & 0.1 & 0.405 & 0.957 & 1.062 & 64.034 \\
\hline 25 & 0.5 & 0.414 & 0.976 & 1.108 & 13.459 \\
\hline 25 & $\mathbf{I}$ & 0.434 & 0.954 & 1.218 & 7.507 \\
\hline 25 & 2.5 & 0.465 & 0.993 & 1.406 & 3.549 \\
\hline 25 & 5 & 0.549 & 0.843 & 2.069 & 2.782 \\
\hline 50 & 0.1 & 0.605 & 0.748 & 1.347 & 188.963 \\
\hline 50 & 0.5 & 0.601 & 0.784 & 1.321 & 36.959 \\
\hline 50 & I & 0.618 & 0.747 & 1.434 & 20.328 \\
\hline 50 & 2.5 & 0.695 & 0.549 & 2.125 & 12.842 \\
\hline 50 & 5 & 0.754 & 0.44 & 2.985 & 9.537 \\
\hline \multicolumn{6}{|l|}{ MKN45 } \\
\hline 10 & 0.1 & 0.127 & I.785 & 0.878 & 1.549 \\
\hline 10 & 0.5 & 0.299 & 1.07 & 2.365 & 1.546 \\
\hline 10 & $\mathbf{I}$ & 0.351 & 1.247 & 2.943 & 1.103 \\
\hline 10 & 2.5 & 0.524 & 0.96 & 5.665 & 1.276 \\
\hline 10 & 5 & 0.697 & 0.61 & 11.172 & 1.92 \\
\hline 25 & 0.1 & 0.483 & 0.553 & 1.948 & 24.961 \\
\hline 25 & 0.5 & 0.467 & 0.765 & 1.836 & 4.536 \\
\hline 25 & $\mathbf{I}$ & $0.48 I$ & 0.923 & 1.934 & 2.466 \\
\hline 25 & 2.5 & 0.594 & 0.852 & 2.945 & 1.952 \\
\hline 25 & 5 & 0.774 & 0.442 & 6.449 & 3.48 \\
\hline 50 & 0.1 & 0.725 & 0.403 & 2.534 & $|17.69|$ \\
\hline 50 & 0.5 & 0.715 & 0.459 & 2.42 & 21.856 \\
\hline 50 & $I$ & 0.753 & 0.414 & 2.897 & 14.624 \\
\hline 50 & 2.5 & 0.802 & 0.377 & 3.764 & 8.945 \\
\hline 50 & 5 & 0.911 & 0.169 & 8.843 & 17.882 \\
\hline
\end{tabular}

Notes: ffa denotes fraction affected. DRI shows the order of magnitude of dose reduction that is allowed in combination for a given degree of effect as compared with the dose of each drug alone.

that $A R$ could interact with EMT-related genes in other tumors. ${ }^{40-43}$ Accordingly, our results showed significant alteration in the expression of well-known EMT-related genes in GC samples as compared to normal tissues. While Snail, Twist1, $\beta$-catenin and STAT3 were overexpressed in GC tissues, E-cadherin showed notable downregulation. Of particular interest was a strong positive relation found between $A R$ and $\beta$-catenin expression in tumor tissues, which was in agreement with several studies demonstrating the direct interaction between the aforementioned genes especially in prostate cancer. ${ }^{41,42,44}$ In a thought-provoking study on HCC, it was also indicated that AR can promote uncontrolled cell proliferation through regulation of cell cycle related kinase to activate $\beta$-catenin/TCF signaling. ${ }^{16}$ Taken together and as the most straightforward interpretation of our results, we presumed that $\mathrm{AR}$ and $\beta$-catenin may have an entwined connection for the progression of EMT and metastasis in GC.

Since the prognosis of advanced GC is dramatically poor, identification of proper markers that precisely predict aggressiveness and progression of the disease could improve the outcome of GC patients. In this study, not only did the results of the Kaplan-Meier analysis reveal that AR, Snail and Twist1 overexpression were significantly correlated with the overall survival of GC patients, but also assessing HR using univariate Cox regression 
model showed that they were remarkable risk factor for the disease prognosis; notably, after adjustment with other variables, we found that AR, Snail and Twistl overexpression cannot be used as independent prognostic factors. Although these results are consistent with a previous report, ${ }^{8}$ Kominea et al claimed a controversial issue suggesting that $\mathrm{AR}$ is an independent prognostic factor for GC patients $^{11}$ which may be explained, at least partly, by different cutoff points, experimental methods, sample size, or different populations that were assessed. To the best of our knowledge, no study has addressed simultaneous assessment of $A R$ and EMT-related gene expressions and this study represents for the first time that concurrent overexpression of $A R$ and Snail can be used as a precise independent unfavorable factor for $\mathrm{GC}$ OS $(\mathrm{HR}=2.382$, $P=0.021$ ).

Given our results showing $A R$ overexpression in GC tissues on the one hand, and controversial findings concerning hormonal therapy using sex hormone receptors antagonists on the other hand this encouraged us to investigate the effect of a novel AR antagonist ENZ in GC cell lines. Our results showed that ENZ, as an FDA-approved drug for metastatic castration-resistant prostate cancer patients, ${ }^{27}$ could significantly inhibit GC cell growth and proliferation in time- and concentration-dependent manners. Our supplementary examinations further support our results that activating AR using an AR agonist DHT could effectively induce GC cell proliferation which is consistent with a study showing that AR activation promoted HCC growth by the suppression of DNA damage repairing system. ${ }^{12}$ Anti-tumor effect of AR inhibition using ENZ was further confirmed using flow cytometric and molecular investigations of cell cycle and apoptosis, where we found that ENZ could regulate G2/M transition and provoke apoptosis via downregulation of cyclin-B1 and $C d k 1$ as well as upregulation of $p 21$ and caspase-3 in GC cell lines. We also authenticated activation of caspase-3 following ENZ treatment using Western blot analysis. In a study on triple-negative breast cancer, Zhu et al showed that AR inhibition using bicalutamide induced apoptosis and exerted an inhibitory effect on cell growth by regulating $\mathrm{p} 21, \mathrm{p} 73$, and cyclin D1 expressions. ${ }^{45}$ Apart from ENZ cytotoxicity, our results showed that AR suppression could overwhelm the ability of GC cell lines to migrate and invade possibly through modulation of EMTrelated genes expression and suppression of MMPs. Taken altogether and to provide a better overview with respect to our results, we provided a schematic model of the possible complex network in which AR crosstalks with EMT- and survival-related pathways to promote progression and metastasis of gastric cancer (Figure 7).

Despite the achievement of magnificent breakthroughs to improve GC survival, the most important factor causing failure in the treatment strategy of the disease is the acquisition of chemoresistance. Bearing this in mind, many studies have been lately dedicated to find innovative targeted therapy, in particular in the context of combinedmodal strategy with traditional chemotherapy. Since the most well-known chemotherapy regime admitted for GC is 5 -FU monotherapy or as part of a combination therapy, ${ }^{46}$ we wondered if ENZ could augment its cytotoxic effects. Our findings suggest that combination of ENZ with even

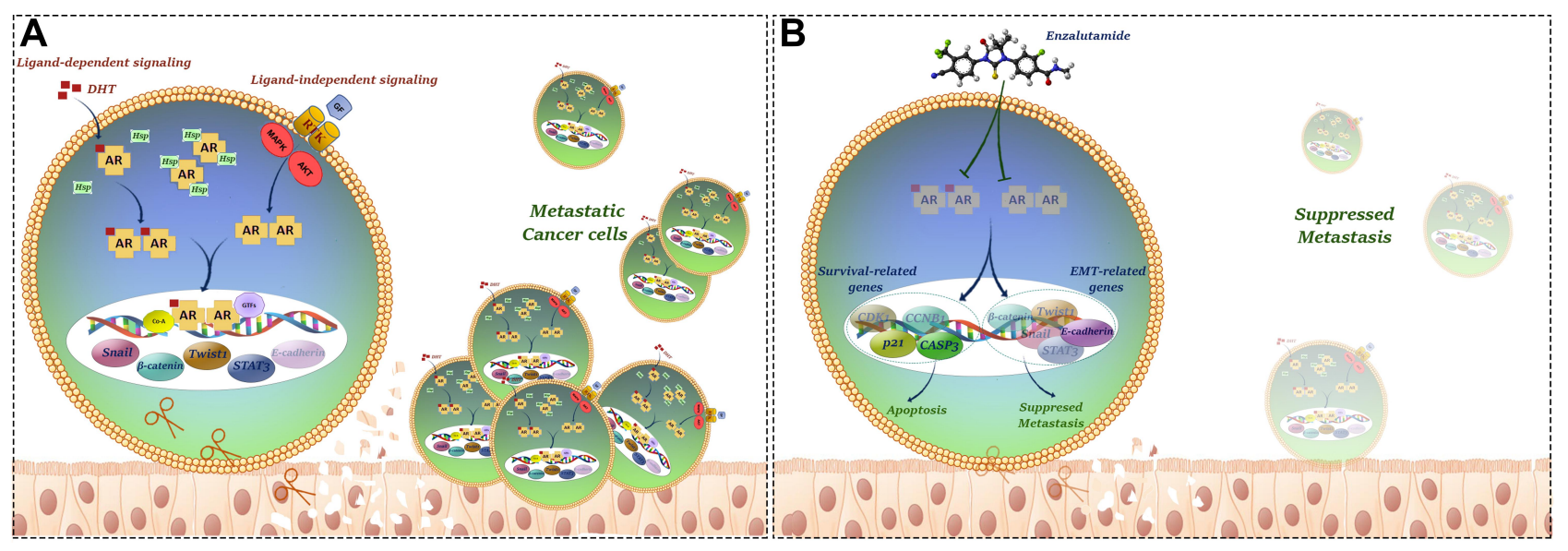

Figure 7 Schematic model of the possible complex network in which AR crosstalks with apoptosis, cell cycle and EMT-related pathways to promote growth, proliferation and metastasis of gastric cancer. (A) Metastatic gastric cancer cells. (B) Inhibition of invasion by ENZ in gastric cancer cells. AR inhibition using ENZ suppressed metastatic properties of the cells through modulation of EMT and survival related-gene expressions. 
low concentration of 5-FU $(0.1 \mu \mathrm{M})$ could attain synergistic effects; highlighting the fact that AR inhibition using ENZ, either as a single agent or in combination with chemotherapy, could provide a better therapeutic outcome in GC patients. However, further researches especially in vivo studies are required to illustrate the accurate impact of AR in GC carcinogenesis along with assessment of antiAR therapy in GC patients.

\section{Abbreviations}

$\mathrm{AR}$, androgen receptor; GC, gastric cancer; EMT, epithelial-mesenchymal transition; ENZ, enzalutamide; DHT, dihydrotestosterone; 5-FU, 5-fluorouracil.

\section{Data Sharing Statement}

All data generated or analyzed during this study and its supplementary information files are included in this published article.

\section{Ethics Approval}

Our research was approved by the Clinical Research Ethics Committee of Tehran University of Medical School (TUMS) and complied with the ethical principles of the HORC-SCT, Shariati hospital and the Helsinki Declaration of 1964 and later versions (Ethics Committee approval code: ir.TUMS.horcsct.rec.1394.103.10).

\section{Consent to Participate}

All participating patients or their immediate family members signed the informed consents.

\section{Acknowledgments}

This study was supported by a grant from Hematology/ Oncology and Stem Cell Transplantation Research Centre, Shariati hospital, Tehran University of Medical Sciences, Tehran, Iran. (Grant numbers: 94-03-36-30292, 94-03-3630293).

\section{Author Contributions}

All authors made substantial contributions to conception and design, acquisition of data, or analysis and interpretation of data; took part in drafting the article or revising it critically for important intellectual content; agreed to submit to the current journal; gave final approval of the version to be published; and agree to be accountable for all aspects of the work.

\section{Funding}

This study was supported by a grant from Hematology, Oncology and Stem Cell Transplantation Research Institute, Shariati hospital, Tehran University of Medical Sciences, Tehran, Iran. (Grant numbers: 94-03-36-30292, 94-03-36-30293).

\section{Disclosure}

The authors report no conflicts of interest in this work.

\section{References}

1. Zhang BG, Du T, Zang MD, et al. Androgen receptor promotes gastric cancer cell migration and invasion via AKT-phosphorylation dependent upregulation of matrix metalloproteinase 9. Oncotarget. 2014;5(21):10584-10595. doi:10.18632/oncotarget.2513

2. Koizumi W, Narahara H, Hara T, et al. S-1 plus cisplatin versus S-1 alone for first-line treatment of advanced gastric cancer (SPIRITS trial): a Phase III trial. Lancet Oncol. 2008;9(3):215-221. doi:10.1016/S1470-2045(08)70035-4

3. Catalano V, Labianca R, Beretta GD, Gatta G, de Braud F, Van Cutsem E. Gastric cancer. Crit Rev Oncol Hematol. 2009;71 (2):127-164. doi:10.1016/j.critrevonc.2009.01.004

4. Tian Y, Wan H, Lin Y, Xie X, Li Z, Tan G. Androgen receptor may be responsible for gender disparity in gastric cancer. Med Hypotheses. 2013;80(5):672-674. doi:10.1016/j.mehy.2013.01.023

5. Siegel RL, Miller KD, Jemal A. Cancer statistics, 2019. CA Cancer J Clin. 2019;69(1):7-34. doi:10.3322/caac.21551

6. Qin J, Liu M, Ding Q, et al. The direct effect of estrogen on cell viability and apoptosis in human gastric cancer cells. Mol Cell Biochem. 2014;395(1-2):99-107. doi:10.1007/s11010-014-2115-2

7. Gan L, He J, Zhang X, et al. Expression profile and prognostic role of sex hormone receptors in gastric cancer. BMC Cancer. 2012;12 (1):566. doi:10.1186/1471-2407-12-566

8. Tang W, Liu R, Yan Y, et al. Expression of estrogen receptors and androgen receptor and their clinical significance in gastric cancer. Oncotarget. 2017;8(25):40765.

9. Wang M, Pan JY, Song GR, Chen HB, An LJ, Qu SX. Altered expression of estrogen receptor alpha and beta in advanced gastric adenocarcinoma: correlation with prothymosin alpha and clinicopathological parameters. Eur J Surg Oncol. 2007;33(2):195-201. doi:10.1016/j.ejso.2006.09.009

10. Nakamura Y, Shimada N, Suzuki T, et al. In situ androgen production in human gastric carcinoma-androgen synthesizing and metabolizing enzymes. Anticancer Res. 2006;26(3A):1935-1939.

11. Kominea A, Konstantinopoulos PA, Kapranos N, et al. Androgen receptor (AR) expression is an independent unfavorable prognostic factor in gastric cancer. J Cancer Res Clin Oncol. 2004;130(5):253258. doi:10.1007/s00432-003-0531-x

12. Ma WL, Hsu CL, Wu MH, et al. Androgen receptor is a new potential therapeutic target for the treatment of hepatocellular carcinoma. Gastroenterology. 2008;135(3):947-955, 955 e941-945. doi:10.1053/j.gastro.2008.05.046

13. Li Y, Izumi K, Miyamoto H. The role of the androgen receptor in the development and progression of bladder cancer. Jpn J Clin Oncol. 2012;42(7):569-577. doi:10.1093/jjco/hys072

14. Konduri S, Schwarz MA, Cafasso D, Schwarz RE. Androgen receptor blockade in experimental combination therapy of pancreatic cancer. J Surg Res. 2007;142(2):378-386. doi:10.1016/j.jss.2006.09.034

15. Miyamoto H, Yang Z, Chen YT, et al. Promotion of bladder cancer development and progression by androgen receptor signals. J Natl Cancer Inst. 2007;99(7):558-568. doi:10.1093/jnci/djk113 
16. Feng H, Cheng AS, Tsang DP, et al. Cell cycle-related kinase is a direct androgen receptor-regulated gene that drives beta-catenin/T cell factor-dependent hepatocarcinogenesis. J Clin Invest. 2011;121 (8):3159-3175. doi:10.1172/JCI45967

17. Boix L, Castells A, Bruix J, et al. Androgen receptors in hepatocellular carcinoma and surrounding liver: relationship with tumor size and recurrence rate after surgical resection. J Hepatol. 1995;22 (6):616-622. doi:10.1016/0168-8278(95)80217-7

18. Kanda T, Jiang X, Yokosuka O. Androgen receptor signaling in hepatocellular carcinoma and pancreatic cancers. World $J$ Gastroenterol. 2014;20(28):9229-9236. doi:10.3748/wjg.v20. i28.9229

19. Okitsu K, Kanda T, Imazeki F, et al. Involvement of interleukin-6 and androgen receptor signaling in pancreatic cancer. Genes Cancer. 2010;1(8):859-867. doi:10.1177/1947601910383417

20. Jukic Z, Radulovic P, Stojkovic R, et al. Gender difference in distribution of estrogen and androgen receptors in intestinal-type gastric cancer. Anticancer Res. 2017;37(1):197-202. doi:10.21873/ anticanres. 11306

21. Fard SS, Saliminejad K, Sotoudeh M, et al. The correlation between EGFR and androgen receptor pathways: a novel potential prognostic marker in gastric cancer. Anticancer Agents Med Chem. 2019;19 (17):2097-2107. doi:10.2174/1871520619666190930142820

22. Kawahara T, Ide H, Kashiwagi E, et al. Enzalutamide inhibits androgen receptor-positive bladder cancer cell growth. Urol Oncol. 2016;34(10):432e415-423. doi:10.1016/j.urolonc.2016.05.016

23. Ao J, Meng J, Zhu L, et al. Activation of androgen receptor induces ID1 and promotes hepatocellular carcinoma cell migration and invasion. Mol Oncol. 2012;6(5):507-515. doi:10.1016/j. molonc.2012.06.005

24. Kanda T, Takahashi K, Nakamura M, et al. Androgen receptor could be a potential therapeutic target in patients with advanced hepatocellular carcinoma. Cancers. 2017;9(5). doi:10.3390/cancers9050043

25. Min A, Jang H, Kim S, et al. Androgen receptor inhibitor enhances the antitumor effect of PARP inhibitor in breast cancer cells by modulating DNA damage response. Mol Cancer Ther. 2018;17 (12):2507-2518. doi:10.1158/1535-7163.MCT-18-0234

26. Sternberg CN. Enzalutamide, an oral androgen receptor inhibitor for treatment of castration-resistant prostate cancer. Future Oncol. 2019;15(13):1437-1457. doi:10.2217/fon-2018-0940

27. Mateo J, Smith A, Ong M, de Bono JS. Novel drugs targeting the androgen receptor pathway in prostate cancer. Cancer Metastasis Rev. 2014;33(2-3):567-579. doi:10.1007/s10555-013-9472-2

28. Schmittgen TD, Livak KJ. Analyzing real-time PCR data by the comparative C(T) method. Nat Protoc. 2008;3(6):1101-1108. doi:10.1038/nprot.2008.73

29. Soleymani Fard S, Jeddi Tehrani M, Ardekani AM. Prostaglandin E2 induces growth inhibition, apoptosis and differentiation in $\mathrm{T}$ and $\mathrm{B}$ cell-derived acute lymphoblastic leukemia cell lines (CCRF-CEM and Nalm-6). Prostaglandins Leukot Essent Fatty Acids. 2012;87 (1):17-24. doi:10.1016/j.plefa.2012.04.012

30. Chou T-C. Drug combination studies and their synergy quantification using the Chou-Talalay method. Cancer Res. 2010;70(2):440-446. doi:10.1158/0008-5472.CAN-09-1947

31. Momeny M, Sabourinejad Z, Zarrinrad G, et al. Anti-tumour activity of tivozanib, a pan-inhibitor of VEGF receptors, in therapy-resistant ovarian carcinoma cells. Sci Rep. 2017;7(1):45954. doi:10.1038/ srep45954
32. Malaguarnera R, Sacco A, Morcavallo A, et al. Metformin inhibits androgen-induced IGF-IR up-regulation in prostate cancer cells by disrupting membrane-initiated androgen signaling. Endocrinology. 2014;155(4):1207-1221. doi:10.1210/en.2013-1925

33. Zhang Y, Pan T, Zhong X, Cheng C. Androgen receptor promotes esophageal cancer cell migration and proliferation via matrix metalloproteinase 2. Tumour Biol. 2015;36(8):5859-5864. doi:10.1007/ s13277-015-3257-x

34. Zhang X, Yashiro M, Qiu H, Nishii T, Matsuzaki T, Hirakawa K. Establishment and characterization of multidrug-resistant gastric cancer cell lines. Anticancer Res. 2010;30(3):915-921.

35. Drake CG, Sharma P, Gerritsen W. Metastatic castration-resistant prostate cancer: new therapies, novel combination strategies and implications for immunotherapy. Oncogene. 2014;33(43):50535064. doi:10.1038/onc.2013.497

36. Kawanishi K, Doki Y, Shiozaki H, et al. Correlation between loss of E-cadherin expression and overexpression of autocrine motility factor receptor in association with progression of human gastric cancers. $\mathrm{Am}$ $J$ Clin Pathol. 2000;113(2):266-274. doi:10.1309/JH4Q-25Q50TRV-W99U

37. Xing X, Tang YB, Yuan G, et al. The prognostic value of E-cadherin in gastric cancer: a meta-analysis. Int J Cancer. 2013;132(11):25892596. doi:10.1002/ijc. 27947

38. Clements WM, Wang J, Sarnaik A, et al. Beta-catenin mutation is a frequent cause of Wnt pathway activation in gastric cancer. Cancer Res. 2002;62(12):3503-3506.

39. Ikenoue T, Ijichi H, Kato N, et al. Analysis of the beta-catenin/T cell factor signaling pathway in 36 gastrointestinal and liver cancer cells. Jpn J Cancer Res. 2002;93(11):1213-1220. doi:10.1111/j.13497006.2002.tb01226.x

40. Liu YN, Liu Y, Lee HJ, Hsu YH, Chen JH. Activated androgen receptor downregulates E-cadherin gene expression and promotes tumor metastasis. Mol Cell Biol. 2008;28(23):7096-7108. doi:10.1128/MCB.00449-08

41. Verras M, Brown J, Li X, Nusse R, Sun Z. Wnt3a growth factor induces androgen receptor-mediated transcription and enhances cell growth in human prostate cancer cells. Cancer Res. 2004;64 (24):8860-8866. doi:10.1158/0008-5472.CAN-04-2370

42. Yang F, Li X, Sharma M, et al. Linking beta-catenin to androgensignaling pathway. $J$ Biol Chem. 2002;277(13):11336-11344. doi:10.1074/jbc.M111962200

43. Junicho A, Matsuda T, Yamamoto T, et al. Protein inhibitor of activated STAT3 regulates androgen receptor signaling in prostate carcinoma cells. Biochem Biophys Res Commun. 2000;278(1):9-13. doi:10.1006/bbrc. 2000.3753

44. Lee E, Madar A, David G, Garabedian MJ, Dasgupta R, Logan SK. Inhibition of androgen receptor and beta-catenin activity in prostate cancer. Proc Natl Acad Sci U S A. 2013;110(39):15710-15715. doi:10.1073/pnas.1218168110

45. Zhu A, Li Y, Song W, et al. Antiproliferative effect of androgen receptor inhibition in mesenchymal stem-like triple-negative breast cancer. Cell Physiol Biochem. 2016;38(3):1003-1014. doi:10.1159/ 000443052

46. Marin JJ, Al-Abdulla R, Lozano E, et al. Mechanisms of resistance to chemotherapy in gastric cancer. Anticancer Agents Med Chem. 2016;16(3):318-334. doi:10.2174/1871520615666150803125121 


\section{Publish your work in this journal}

OncoTargets and Therapy is an international, peer-reviewed, open access journal focusing on the pathological basis of all cancers, potential targets for therapy and treatment protocols employed to improve the management of cancer patients. The journal also focuses on the impact of management programs and new therapeutic

Submit your manuscript here: https://www.dovepress.com/oncotargets-and-therapy-journa agents and protocols on patient perspectives such as quality of life, adherence and satisfaction. The manuscript management system is completely online and includes a very quick and fair peer-review system, which is all easy to use. Visit http://www.dovepress.com/ testimonials.php to read real quotes from published authors. 